\title{
O DESENVOLVIMENTO DO INTERESSE DA DOCÊNCIA NO CONTEXTO DO PROGRAMA DA RESIDÊNCIA PEDAGÓGICA EM CIÊNCIAS BIOLÓGICAS
}

\author{
Rosa Shizue $A B E^{1}$ \\ Sérgio de Mello ARRUDA ${ }^{2}$ \\ Maria Ida LIMA ${ }^{3}$ \\ Lucken Bueno LUCAS ${ }^{4}$
}

\begin{abstract}
Resumo
Esta pesquisa trata de um estudo sobre o desenvolvimento do interesse pela docência, a partir de um grupo de acadêmicos de Licenciatura em Ciências Biológicas, participantes do Programa Residência Pedagógica. Teve como objetivo investigar o interesse deles pela docência a partir deste Programa que os levou à prática docente. Eles foram entrevistados e suas respostas analisadas a partir do referencial da Análise Textual Discursiva. Fundamentadas no Modelo de Quatro Fases do Desenvolvimento do Interesse, as categorias de análise efetivadas evidenciaram que elementos externos acionadores do despertar do interesse favoreceram à permanência dos licenciandos no Programa, e que sua participação em ações formativas congêneres e anteriores, assim como nas atividades propostas ao longo da Residência Pedagógica, contribuíram para sua permanência na licenciatura, promovendo desenvolvimento individual no âmbito da docência.
\end{abstract}

Palavras-chaves: Interesse pela docência. Modelo de Quatro Fases do Desenvolvimento do Interesse (MDI). Programa da Residência Pedagógica.

\footnotetext{
${ }^{1}$ Mestra em Ensino (PPGEN/UENP). Professora efetiva de Ciências da Rede Estadual do estado do Paraná. ORCID: https://orcid.org/0000-0001-7820-8483.

E-mail: rosashizuecontardi@gmail.com.

${ }^{2}$ Doutor em Educação (USP). Professor permanente do Programa de Pós-graduação em Ensino de Ciências e Educação Matemática da Universidade Estadual de Londrina (PECEM/UEL); professor permanente do Programa de Pósgraduação em Ensino da Universidade Estadual do Norte do Paraná (PPGEN/UENP). ORCID: https://orcid.org/00000002-4149-2182. Com apoio do CNPq.

E-mail: sergioarruda@uel.br.

${ }^{3}$ Mestra em Ensino (PPGEN/UENP). Professora efetiva de Ciências da Rede Estadual do estado do Paraná. ORCID: https: //orcid.org/0000-0002-3522-3138.

E-mail: mariaidalima01@gmail.com.

${ }^{4}$ Doutor em Ensino de Ciências e Educação Matemática (UEL). Professor efetivo do curso de Ciências Biológicas e do Programa de Pós-Graduação em Ensino da Universidade Estadual do Norte do Paraná (PPGEN/UENP). ORCID https://orcid.org/0000-0003-2122-867.

E-mail: luckenlucas@uenp.edu.br.
} 


\title{
THE DEVELOPMENT OF INTEREST IN TEACHING IN THE CONTEXT OF THE PEDAGOGICAL RESIDENCY PROGRAM IN BIOLOGICAL SCIENCES
}

\author{
Rosa Shizue ABE \\ Sérgio de Mello ARRUDA \\ Maria Ida LIMA \\ Lucken Bueno LUCAS
}

\begin{abstract}
This research focuses on a study of the development of interest in teaching, from a group of undergraduate student teachers in Biological Sciences, participating in the Pedagogical Residency Program. The objective was to investigate the interest of the student teachers in teaching after this Program which involved teaching practice. The students were interviewed and their responses were analyzed using the Discursive Textual Analysis reference. Based on the Four Phase Model of Interest Development, the categories of analysis showed that external elements that triggered the awakening of interest favored the permanence of undergraduates in the Program, and that the participation in similar and previous teacher education actions, as well as the activities proposed throughout the Pedagogical Residency, contributed to permanence in the degree, promoting individual development in the area of teaching.
\end{abstract}

Keywords: Interest in teaching. Four Phase Model of Interest Development (FPMID). Pedagogical Residency Program. 


\title{
EL DESARROLLO DE INTERÉS DOCENTE EN EL CONTEXTO DEL PROGRAMA DE RESIDENCIA PEDAGÓGICA EN CIENCIAS BIOLÓGICAS
}

\author{
Rosa Shizue ABE \\ Sérgio de Mello ARRUDA \\ Maria Ida LIMA \\ Lucken Bueno LUCAS
}

\begin{abstract}
Resumen
Esta investigación trata de un estudio sobre el desarrollo por el Interés en la docencia, a partir de un grupo de académicos de la Licenciatura en Ciencias Biológicas, participantes del programa Residencia pedagógica. Tuvo como objetivo el interés de ellos por la docencia partiendo de este Programa, el cual los llevó a la práctica docente. Ellos fueron entrevistados y sus respuestas analizadas a la luz del referencial de Análisis Textual Discursivo. Fundamentados en el modelo de Cuatro Fases del Desarrollo de Interés, las categorías de análisis efectuadas mostraron elementos externos encargados del despertar por este interés y que favorecieron la permanencia de los licenciados en el Programa, además que, su participación en acciones formativas congéneres y anteriores, así como en las actividades propuestas a lo largo de la Residencia Pedagógica, contribuyeron para la permanencia en la licenciatura, promoviendo el desarrollo individual en el ámbito de la docencia.
\end{abstract}

Palabras Clave: Interés por la docencia. Modelo de Cuatro Fases del Desarrollo de Interés (MDI). Programa de Residencia pedagógica. 


\section{Introdução}

A formação de bons professores está relacionada à melhoria da qualidade da Educação Básica e às reformas educacionais. Mantêm a mesma relação, os estudos de alguns pesquisadores que também convergem para essa temática. Por isso, no âmbito da formação inicial, algumas Políticas Públicas têm favorecido a imersão de futuros professores no ambiente escolar.

O Programa Residência Pedagógica (PRP) é uma das ações governamentais mais recentes voltadas à formação e ao incentivo para o magistério. Nele, os estudantes de licenciatura, denominados 'residentes pedagógicos', vivenciam situações reais da docência juntamente com profissionais mais experientes, como acontece de modo similar à ideia da residência médica. Embora a profissão de professor seja tão desvalorizada e pouco atrativa no Brasil, os cursos de licenciatura recebem os jovens e os convidam a participar de programas como a Residência Pedagógica, que se apresenta como uma boa oportunidade para melhorar seu processo formativo. Mas, de fato, os participantes desse Programa estão interessados pela docência?

De acordo com Houaiss (2011, p. 546), o vocábulo ‘interesse’ tem vários significados: “[...] I) o que é importante, útil ou vantajoso, II) simpatia ou curiosidade por algo; III) importância dada a algo; IV) apego ao que traz vantagem pessoal”.

No contexto do PRP, para formar bons professores é preciso aprender a ser um deles “[...] e a aprendizagem da docência passa pelo interesse e pela disponibilidade do futuro professor para a docência (ARRUDA, PASSOS; FREGOLENTE, 2012, p. 29).

Para Hidi, Renninger e Krapp (2004) o interesse é entendido como um estado psicológico resultante da interação entre pessoas e aquilo que os interessa, gerando aumento de atenção, concentração e também afeto. Desse modo, o objetivo desta pesquisa consistiu em investigar o interesse pela docência de um grupo de estudantes de um curso de Licenciatura em Ciências Biológicas, participantes do Programa Residência Pedagógica. Nas próximas seções apresentamos a fundamentação teórica que norteou o processo investigativo.

\section{O programa residência pedagógica (PRP)}

O Programa Residência Pedagógica é uma ação modelizada e modernizada do Programa Institucional de Bolsas de Iniciação à Docência (PIBID) voltado para os licenciandos matriculados 
na metade de seu curso. De acordo com o edital 06/2018 - CAPES ${ }^{5}$, as Instituições de Ensino Superior (IES) interessadas foram selecionadas para conduzir os acadêmicos, a partir do ano subsequente, às escolas públicas de Educação Básica cadastradas. Como estratégia de reformular o estágio supervisionado, as IES puderam pensar sua participação no PRP. Aos residentes, estudantes da licenciatura, coube o cumprimento de 440 horas de atividades das quais 100 incluíram regências (planejamento e execução de pelo menos uma intervenção pedagógica), sempre acompanhados por docentes da Educação Básica, os 'preceptores’ ${ }^{\text {. }}$

São destinadas bolsas (apoio financeiro) aos participantes do PRP, embora assim como no PIBID, o Programa possibilite a participação de voluntário. O que se espera dos estudantes é a sua inserção no cotidiano escolar, para aprender com professores mais experientes a planejar práticas didático-pedagógicas, vivenciar os conflitos reais e superar as adversidades da profissão. O PRP apresenta quatro objetivos, segundo a CAPES (Edital n. 06/2018):

1. Aperfeiçoar a formação dos discentes de cursos de licenciatura, por meio do desenvolvimento de projetos que fortaleçam o campo da prática e conduzam o licenciando a exercitar de forma ativa a relação entre teoria e prática profissional docente, utilizando coleta de dados e diagnóstico sobre o ensino e a aprendizagem escolar, entre outras didáticas e metodologias;

2. Induzir a reformulação da formação prática nos cursos de licenciatura, tendo por base a experiência da residência pedagógica;

3. Fortalecer, ampliar e consolidar a relação entre a IES e a escola, promovendo sinergia entre a entidade que forma e a que recebe o egresso da licenciatura e estimulando o protagonismo das redes de ensino na formação de professores;

4. Promover a adequação dos currículos e propostas pedagógicas dos cursos de formação inicial de professores da educação básica às orientações da Base Nacional Comum Curricular (BRASIL, 2018).

No que tange à melhoria da formação docente inicial, frente aos objetivos da PRP, pensamos que alguns aspectos da formação de professores precisam ser repensados. Por isso, encontramos no referencial de Arruda, Passos e Fregolente (2012) um caminho para ampliar nossa compreensão sobre quais seriam os pontos fortes a serem trabalhados no referido processo formativo, como apresentamos seguidamente.

\footnotetext{
${ }^{5}$ Coordenação de Aperfeiçoamento de Pessoal de Nível Superior- fundação ligada ao Ministério da Educação. Disponível em <https://www.capes.gov.br/images/stories/download/editais/01032018-Edital-6-2018-Residenciapedagogica.pdf_> Acesso em 10 out 2020.

${ }^{6}$ De acordo com o edital da CAPES (2018), a nomenclatura “supervisor” é substituída por “preceptor” para denominar o professor da Educação Básica, que acompanha os residentes pedagógicos em sala de aula.
} 


\section{Os focos da aprendizagem docente (FAD) e o modelo do desenvolvimento do interesse (MDI)}

Os Focos da Aprendizagem Docente (FAD) são instrumentos para analisar o aprendizado da docência (ARRUDA, PASSOS e FREGOLENTE, 2012). Segundo seus autores, os FAD permitem evidenciar a aprendizagem docente, a partir de cinco categorias de análise também chamadas de significantes: o interesse pela docência, o conhecimento prático da docência, a reflexão sobre a docência, a comunidade docente e a identidade docente, cujos focos estão especificados no Quadro 1.

\section{Quadro 01 - Focos da Aprendizagem Docente (FAD)}

Foco 1 [Interesse pela docência]: O estudante experimenta interesse, envolvimento emocional, curiosidade, motivação, mobilizando-se para exercer e aprender cada vez mais sobre a docência.

Foco 2 [Conhecimento prático da docência]: A partir do conhecimento na ação e com base na reflexão na ação, o estudante desenvolve o conhecimento de casos, um repertório de experiências didáticas e pedagógicas que orientam a sua prática cotidiana in actu.

Foco 3 [Reflexão sobre a docência]: Frente a novos problemas originados de sua prática, os quais não conseguiu resolver no momento em que ocorriam, o futuro professor, com base em instrumentos teóricos, analisa a situação sistematicamente, envolvendo-se com a pesquisa e reflexão a posteriori sobre sua prática e o seu conhecimento acumulado sobre ela, de modo a resolver os problemas inicialmente detectados. Trata-se de desenvolver a dimensão da pesquisa no futuro professor.

Foco 4 [Comunidade docente]: O estudante participa de atividades desenvolvidas em uma comunidade docente, aprende as práticas e a linguagem da docência com outros professores ou futuros professores, assimilando valores dessa comunidade e desenvolvendo a reflexão coletiva.

Foco 5 [Identidade docente]: O estudante pensa sobre si mesmo como um aprendiz da docência e desenvolve uma identidade como alguém que se tornará futuramente um professor de profissão.

Fonte: Arruda, Passos, Fregolente (2012, p. 32- 33).

Os FAD já foram testados em ambientes de educação informal como museus, em programas de formação inicial como o $\operatorname{PIBID}^{7}$ (licenciandos, coordenadores, supervisores, exbolsistas) de Física, Química e Biologia, com professores em serviço, com licenciandos e seus formadores e até mesmo em curso de licenciatura em Biologia à distância (ARRUDA, PORTUGAL, PASSOS, 2018).

Também foram utilizados separadamente, como o foco do interesse na aprendizagem docente (Foco 1) dos estudantes de Ciências Biológicas, Física e Química, no contexto do PIBID (MARTIN; ARRUDA; PASSOS, 2016). E é nesse trabalho que pautamos essa atividade investigativa. Para compreender o foco do interesse, os autores se aprofundaram no Modelo de quatro Fases do

\footnotetext{
${ }^{7}$ PIBID - Programa Institucional de Bolsa de Iniciação à Docência, um Programa nacional também voltado à formação inicial de professores, anterior ao Programa Residência Pedagógica.
} 
Desenvolvimento do Interesse (MDI) de Hidi e Renninger (2006), que consiste num instrumento de análise do interesse pelas fases que o compõem (MARTIN, ARRUDA, PASSOS, 2016).

Para Hidi e Renninger (2006), o interesse é o estado psicológico do sujeito frente ao objeto e, seu desenvolvimento está associado aos elementos de afeto (sentimentos positivos ou negativos), de conhecimento e de valor. Se houver fatores de apoio (ambientais ou externos), o interesse passa para outra fase com persistência e aumento de seu nível, e pode prosseguir até a outra fase. Cada uma delas, por sua vez, está relacionada ao nível de envolvimento pessoal, à presença de apoios, à duração da envoltura no objeto de interesse, a graus de esforços e ao autodomínio. As quatro fases do Modelo de Hidi e Renninger sobre o Desenvolvimento do Interesse (MDI) são:

Fase 1: Interesse Situacional Acionado. Refere-se a um estado psicológico de disposição, interesse ou vontade que é consequência de alterações, normalmente de curto prazo, em processos de natureza afetiva (sentimentos positivos ou negativos) e cognitiva, sendo comparável com um gatilho motivacional. Essa modalidade de interesse é resultado de um processo de desenvolvimento do interesse que resulta de interações ambientais, sempre externas ao sujeito. Qualquer elemento pode ativar o Interesse Situacional Acionado, desde que relacionado a elementos com relevância pessoal de grande intensidade.

Fase 2: Interesse Situacional Mantido. Refere-se a um estado psicológico de disposição, interesse ou vontade, que decorre da ou sucede a primeira Fase. Diferente da Fase 1, o interesse aqui é temporalmente persistente e costuma ser mantido por atividades significativas que sustentem o envolvimento pessoal em determinadas atividades; também difere quando destaca que este pode estar relacionado a elementos externos, mas isso não é obrigatório, já que elementos subjetivos podem implicar na manutenção, ou prolongamento temporal, da disposição, interesse ou vontade. É característica, a partir desta Fase, a presença de sentimentos positivos pelo assunto ou evento de interesse. A persistência temporal do interesse está relacionada ao desenvolvimento de atividades significativas ou subjetivamente envolventes.

Fase 3: Interesse Individual Emergente. Refere-se a um estado psicológico de disposição, interesse ou vontade, relacionado a disposições subjetivas e afetivas relativamente duradouras para o envolvimento com atividades de longo período. Distinta da Fase 2, ela é caracterizada pela articulação de conhecimentos, valores e sentimentos positivos que mantêm o indivíduo vinculado ao objeto de interesse. Vê-se, com isso, que os elementos da motivação são preponderantemente disposições subjetivas, embora o apoio ambiental ou externo ainda não possa ser descartado. Por exemplo, pode ser fundamental o encorajamento para a manutenção do Interesse Individual Emergente em determinada atividade. Lastreado em desenvolvimentos anteriores, o sujeito valoriza o envolvimento em situações, tarefas ou atividades relacionadas ao seu Interesse Individual Emergente, preferindo-as quando lhe for oferecida mais de uma atividade para escolha.

Fase 4: Interesse Individual Bem Desenvolvido. Refere-se a um estado psicológico de disposição, interesse ou vontade, relacionado a sentimentos positivos e mais 
conhecimentos, mais valores. Esta Fase não despreza o Interesse Individual Emergente; na verdade, o abarca. O sujeito nesta Fase encontra-se muito envolvido e motivado, de modo que valoriza a oportunidade de se envolver em atividades ou tarefas para as quais tem Interesse Individual Bem Desenvolvido. Ele está predisposto a ser criativo e é capaz de formular perguntas sobre o conteúdo de interesse e de compreender os processos relacionados com aquele conteúdo. Além disso, quando há esse interesse, o sujeito é capaz de se envolver em atividades criativas e empreendimentos construtivos de longo prazo, que demandam maior e mais profundo envolvimento, além de mais capacidade de desenvolver tarefas. O sujeito conquista autonomia para resolver problemas e tarefas complexas, sendo capaz de se autorregular e se beneficiar do apoio externo, quando necessário. Esse tipo de interesse, portanto, trata de um processo de amplificação da autonomia, que está relacionado ao deslocamento do exterior para o interior dos elementos capazes de articular as disposições, o interesse e a vontade, mas não se esgota nisso (HIDI e RENNINGER, 2006 apud MARTIN, ARRUDA, PASSOS, p. 49-50, 2016).

Assim, com base no FAD 1 - Interesse pela docência (ARRUDA; PASSOS; FREGOLENTE, 2012) e no Modelo de quatro Fases do Desenvolvimento do Interesse (MDI) de Hidi e Renninger (2006) - investigamos em um grupo de licenciandos de Ciências Biológicas, a questão do Interesse pela docência mediante sua participação no Programa Residência Pedagógica. Os encaminhamentos metodológicos da pesquisa são delineados a seguir.

\section{Procedimentos metodológicos}

Nessa pesquisa, de caráter qualitativo, utilizamos como instrumento de coleta de dados uma entrevista semiestruturada que foi aplicada a dez licenciandos, de um curso de Ciências Biológicas de uma Universidade pública do Estado do Paraná, participantes do Programa Residência Pedagógica. Esses participantes apresentavam faixa etária entre 21 e 28 anos, cinco cursavam o $4^{\circ}$ ano e os demais o $5^{\circ}$ ano do curso. Dois deles eram residentes voluntários (não bolsistas) e a mesma quantidade havia cursado o magistério no Ensino Médio.

Após esclarecimento da pesquisa e a obtenção do consentimento da participação, as entrevistas foram áudio gravadas, transcritas e analisadas. Os entrevistados foram codificados nos codificadores E1, E2, E3... E10 e as respostas das questões em Q1, Q2... Q9. As perguntas formuladas e validadas por um grupo de pesquisa da Área de Ensino foram as seguintes: 1. Por que você está participando do Programa Residência Pedagógica? 2. Ao participar da RP, sua visão mudou quanto à docência? Sobre ser professor de Ciências e Biologia? Comente. 3. Você participou de algum evento/curso sobre Ensino de Biologia além do Programa RP? Como foi a experiência? 4. Você pretende ser professor de Ciências/Biologia? Por quê? 5. Participar do PRP contribui para sua formação? Por quê? 6. As reuniões com os preceptores e coordenadores do PRP 
são importantes na sua formação? Comente. 7. Por que escolheu um curso de Licenciatura em Ciências Biológicas? 8. Como foi acompanhar o professor preceptor em sala de aula? Conte sobre essa experiência. 9. Quer comentar algo que não perguntei sobre sua participação do PRP?

A análise dos dados foi baseada nos pressupostos da Análise Textual Discursiva (ATD), iniciando com a fragmentação e o agrupamento de excertos textuais por afinidade semântica (MORAES, GALIAZZI, 2011). Previamente, estabelecemos categorias de análise a partir da pesquisa de Martin, Arruda e Passos (2016), segundo as quatro fases do desenvolvimento do interesse (MDI), conforme o Quadro 02.

Quadro 2 - As Fases do Interesse e suas categorias.

\begin{tabular}{|c|c|c|}
\hline Fases & Categorias prévias & Categorias efetivadas \\
\hline \multirow{3}{*}{$\begin{array}{c}1 \\
\text { Interesse Situacional } \\
\text { Acionado }\end{array}$} & Despertar & Despertar \\
\hline & Elementos relevantes & Elementos relevantes \\
\hline & Informação de persuasão & \\
\hline \multirow{6}{*}{$\begin{array}{c}2 \\
\text { Interesse Situacional } \\
\text { Mantido }\end{array}$} & Atividades significativas & Atividades significativas \\
\hline & $\begin{array}{l}\text { Aprendizagem em grupo } \\
\text { cooperativo }\end{array}$ & $\begin{array}{l}\text { Aprendizagem em grupo } \\
\text { cooperativo }\end{array}$ \\
\hline & Tutoria & Tutoria \\
\hline & & Participação no PRP \\
\hline & Valorização da docência & \\
\hline & $\begin{array}{c}\text { Apropriação de saberes: } \\
\text { como “ser” professor }\end{array}$ & $\begin{array}{c}\text { Apropriação de saberes: } \\
\text { como "ser” professor }\end{array}$ \\
\hline \multirow{4}{*}{$\begin{array}{c}3 \\
\text { Interesse Individual } \\
\text { Emergente }\end{array}$} & $\begin{array}{c}\begin{array}{c}\text { Escolha pela carreira } \\
\text { docente }\end{array} \\
\end{array}$ & $\begin{array}{c}\begin{array}{c}\text { Escolha pela carreira } \\
\text { docente }\end{array} \\
\end{array}$ \\
\hline & $\begin{array}{c}\text { Encontro com a profissão } \\
\text { docente }\end{array}$ & $\begin{array}{c}\text { Encontro com a profissão } \\
\text { docente } \\
\end{array}$ \\
\hline & $\begin{array}{l}\text { Importância das atividades } \\
\text { dos estudantes do PIBID }\end{array}$ & $\begin{array}{c}\text { Importância das atividades } \\
\text { dos estudantes do PIBID }\end{array}$ \\
\hline & & Admiração pelo preceptor \\
\hline \multirow{4}{*}{$\begin{array}{c}4 \\
\text { Interesse Individual Bem } \\
\text { Desenvolvido }\end{array}$} & Vivências em sala de aula & Vivências em sala de aula \\
\hline & $\begin{array}{c}\text { Percalços da profissão } \\
\text { docente }\end{array}$ & $\begin{array}{c}\text { Percalços da profissão } \\
\text { docente }\end{array}$ \\
\hline & Autorregulação & Autorregulação \\
\hline & & $\begin{array}{l}\text { Percepção do estudante } \\
\text { sobre “ser" professor no } \\
\text { contexto do PIBID }\end{array}$ \\
\hline
\end{tabular}

Fonte: Martin, Arruda de Passos (2016) - adaptado.

Em nossa análise dos excertos textuais, a maioria das categorias prévias se efetivou, mas emergiram três novas categorias: “Participação no PIBID”, “Admiração pelo preceptor” e “A pretensão de ser professor”, no contexto do PRP, que substituíram respectivamente as categorias Informação de persuasão (Fase 1), Valorização da docência (Fase 3) e Percepção do estudante sobre “ser” professor no contexto do do PRP (Fase 4), como mostra o Quadro 02. 


\section{Apresentação e análise dos dados}

A análise dos dados foi pensada com base nas quatro fases do desenvolvimento do interesse pelo aprendizado da docência e suas respectivas categorias. Iniciamos com o interesse inicial pela docência, conforme o Quadro 3, Fase 1: Interesse Situacional Acionado, com os excertos textuais dos residentes.

\section{Quadro 3 - Fase 1: Interesse Situacional Acionado}

\begin{tabular}{|c|c|}
\hline \multicolumn{2}{|c|}{$\begin{array}{c}\text { A Fase } 1 \text { - Interesse Situacional Acionado: apresenta as respostas que expressam os momentos } \\
\text { iniciais do desenvolvimento do interesse pela docência. }\end{array}$} \\
\hline Despertar & $\begin{array}{l}\text { Eu entrei no curso no intuito de ser professor no futuro, terminar meu curso e me } \\
\text { tornar professor (E1Q1). } \\
\text { Na realidade eu entrei no curso, mas não me interessava pela área de licenciatura, } \\
\text { então, com o PRP eu poderia participar voluntariamente e me interessei para } \\
\text { aproximar dessa área para ter experiência (E9Q1). } \\
\text { O que me fez entrar no RP é porque eu vi que precisava de conhecimento a mais de } \\
\text { didática, dessa parte de licenciatura. Eu tenho um conhecimento bom de Biologia, } \\
\text { mas se eu precisar passar esse conhecimento para alguém um dia? Eu vou conseguir } \\
\text { passar bem isso? Se eu entrar na sala de aula do nada, como eu vou ficar lá? (E2Q9). } \\
\text { Eu optei em participar da Residência mais para ter essa experiência, para eu aprender } \\
\text { um pouco mais de como é uma sala de aula, ter esse apoio inicialmente de um } \\
\text { professor com mais experiência na área para quando eu esteja lá, para quando muitas } \\
\text { das coisas que eu estiver errando, digamos assim, eu já tenha mais um pouco de } \\
\text { prática, experiência pra agir (E8Q1). }\end{array}$ \\
\hline $\begin{array}{l}\text { Elementos } \\
\text { relevantes }\end{array}$ & $\begin{array}{l}\text { Além de ter uma bolsa que ajuda porque atualmente não estou trabalhando, então a } \\
\text { bolsa ajuda financeiramente (E10Q5). } \\
\text { Para um concurso, PSS que abrir esse certificado já vai me ajudar porque querendo } \\
\text { ou não são } 100 \text { horas que eu tenho lá no batente, como regente (E10Q5). } \\
\text { Eu sou voluntária, eu entrei mais mesmo pra aumentar essa... porque hoje em dia a } \\
\text { gente sabe que tem que ter experiência e tal, então é uma coisa que agrega no meu } \\
\text { currículo (E9Q9) }\end{array}$ \\
\hline
\end{tabular}

Fonte: Elaborado pelos pesquisadores (2020).

Nessa fase, apresentamos as narrativas que expressaram os momentos iniciais do interesse pela docência no PRP. Observamos que E1 já manifestava interesse pela docência ao ingressar no curso, diferentemente de E9 que não se interessava pela licenciatura, mas ingressou voluntariamente no PRP para ter experiência. Já E2 disse sentir a necessidade da parte da 'didática' para poder ensinar o que sabe, enquanto E8 buscou no PRP experiência e conhecimento da sala de aula sob a tutoria de um professor experiente. 
Podemos observar que o despertar do interesse pela docência pode estar associado ao desejo de experimentar como é ser professor, com intuito de aprender a sê-lo relacionado à intenção de ser professor e à necessidade da experiência docente. Como elementos relevantes de interesse pela docência, E10 mencionou o recebimento da bolsa, como ajuda financeira, e a certificação para futuros contratos empregatícios; E9 relatou a importância da participação em seu currículo.

\section{Quadro 4 - Fase 2: Interesse Situacional Mantido}

A Fase 2 - Interesse Situacional Mantido: agrupa os excertos que evidenciam a importância das atividades do PRP realizadas em grupo e com supervisão em sala de aula.

\begin{tabular}{|c|c|}
\hline $\begin{array}{c}\text { Atividades } \\
\text { significativas }\end{array}$ & $\begin{array}{l}\text { Participar da RP está me ajudando a ser licenciado, está agregando conhecimento na } \\
\text { parte de como lidar com os alunos: na sala de aula nem todo mundo vai ficar } \\
\text { paradinho, quietinho prestando atenção, você tem que saber como lidar (E2Q4). } \\
\text { Teve o evento da Integração, eu participei. A gente apresentou lá. Nosso trabalho foi } \\
\text { montado para a gestão de classe, se acontecia por uma boa gestão do professor, ou de } \\
\text { uma boa turma, ou por ser uma escola mais agitada, se os alunos são mais bagunceiros } \\
\text { ou se realmente o professor conseguia ter uma gestão de classe boa.Eu aprendi esse } \\
\text { termo gestão de classe no PIBID (E8Q3). } \\
\text { Teve um worshop de ensino, foi bem legal a participação. Teve uma conversa com o } \\
\text { prof. C. que era docente da universidade e agora está no pós-doutorado: ele deu uma } \\
\text { visão não só da docência, mas também da docência em relação à pesquisa e esse } \\
\text { buraco que a gente tem no meio (E4Q3). }\end{array}$ \\
\hline $\begin{array}{l}\text { Aprendizagem em } \\
\text { grupo cooperativo }\end{array}$ & $\begin{array}{l}\text { Nos encontros da RP, foi pedido que a gente preparasse um plano de aula de Ensino } \\
\text { Médio e aplicássemos durante a reunião, o meu tema foi sobre célula. Também } \\
\text { trouxeram professores da universidade para explicar como se prepara um plano de } \\
\text { aula, sobre as Diretrizes e a gente aprendeu muito não só a parte acadêmica, mas } \\
\text { muito da parte burocrática de ser professor: o que seguir e o que evitar dentro da sala } \\
\text { de aula (E1Q6). } \\
\text { Nas reuniões da RP, as pessoas estavam apresentando o microensino e eu vi a visão de } \\
\text { outros companheiros meus da RP de como eles dão aula e poderia ter algo deles que } \\
\text { eu poderia pegar e usar em minha aula, por exemplo, cartaz, experiências práticas. } \\
\text { Inclusive usei na minha aula de estágio obrigatório que foi a parte das organelas, } \\
\text { células (E2Q5). } \\
\text { A gente tem reuniões sim, e acho legal porque os alunos que fazem parte do projeto } \\
\text { acabam compartilhando experiências e também os professores que estão ali na frente, } \\
\text { como estão há mais tempo fazendo isso, acabam dando dicas pra gente do que pode ou } \\
\text { não fazer. É praticamente uma roda que cada um compartilha suas experiências, e que } \\
\text { cada um acaba ajudando o outro, acho muito importante (E3Q6). } \\
\text { As reuniões das quais eu participei, consegui absorver bastante coisa, como quando } \\
\text { veio uma professora que aplicou um trabalho dela (Contaminação do ambiente) e daí } \\
\text { eu consegui aproximar mais ainda, pois eu consegui entender que não é } \\
\text { necessariamente um único caminho, mas interligar as áreas (E5Q5). } \\
\text { Pra mim foi bem importante porque uma coisa que outro vivenciou [...], um outro } \\
\text { residente citou uma ocasião que ele não soube como agir naquela situação. E dias } \\
\text { depois, eu vivenciei a situação, porém a gente já tinha comentado nas reuniões: o que } \\
\text { seria legal ou não fazer (E8Q6). }\end{array}$ \\
\hline
\end{tabular}




\begin{tabular}{|c|c|}
\hline Tutoria & $\begin{array}{l}\text { Os professores sempre dão dicas de como fazer tal coisa, de coisas que eles já } \\
\text { fizeram que deram ou não certo (E1Q9). } \\
\text { Comecei a observar e identificar cada indivíduo que tinha mais dificuldade, } \\
\text { acompanhava como a professora lidava com isso e consegui interagir com a turma } \\
\text { toda (E5Q7). } \\
\text { Na revisão, o professor fez a retomada de conteúdo e ensinou uma outra forma de } \\
\text { fazer aquilo. Então, pra mim foi um aprendizado muito grande porque eu pude } \\
\text { perceber que a forma pra mim estava sendo bem claro e que eu achava que para os } \\
\text { alunos também era bem claro, eu vi que não era e vi que sempre tem como a gente } \\
\text { achar uma outra forma de explicar para eles [...] é sempre bom retomar aquele } \\
\text { conteúdo de uma outra forma, porque quando a gente olha inicialmente parece que } \\
\text { todo mundo aprendeu, mas não (E8Q8). } \\
\text { A preceptora que eu acompanho, ela sempre tenta dar uma aula prática para os alunos } \\
\text { sempre leva atividade, não se liga muito só no livro. Ela sempre usa outro livro, não } \\
\text { so aquele livro didático do colégio (E10Q6). }\end{array}$ \\
\hline Participação no PRP & $\begin{array}{l}\text { Bom, eu já tinha participado do PIBID ano passado, eu gostei pelo fato de ir a escola, } \\
\text { mas não poderia mais [...], mas poderia fazer o Residência, daí quando abriu o projeto, } \\
\text { me inscrevi e estou lá até hoje(E3Q1). } \\
\text { Eu já fazia o PIBID, sempre gostei da área de ensino e eu achava que seria um estágio } \\
\text { muito bom (E6Q1). } \\
\text { Eu já participei antes do PIBID, eu já gostava, por ter formação no magistério, eu já } \\
\text { tinha um pouco de contato com a docência (E8Q1). } \\
\text { É uma oportunidade de continuação da formação inicial, então eu fiz parte do PIBID, } \\
\text { só que no PIBID a gente observa, participa, mas não chega a ter contato com a } \\
\text { regência. A Residência há a oportunidade de regência mais vezes e ter a chance de } \\
\text { estar num colégio de forma mais vivenciada(E4Q1). }\end{array}$ \\
\hline
\end{tabular}

Fonte: Elaborado pelos pesquisadores (2020).

$\mathrm{Na}$ Fase 2, os relatos mostraram fatos e ações da manutenção ou prolongamento do interesse/vontade relacionados às atividades envolventes. O licenciado E2 relatou sua aprendizagem em lidar com alunos graças ao PRP. A iniciação à pesquisa sobre docência foi comentada por E8 com a apresentação em eventos, enquanto E4 narrou sobre a docência e a pesquisa e o intermédio entre elas. As reuniões do PRP foram consideradas como grupos colaborativos de aprendizagem, nas quais E1 comentou da aprendizagem teórica e prática para atuar em sala de aula. E2 aprendeu recursos didáticos e usou em suas aulas; E3, por sua vez, comentou sobre o processo de aprendizado com professores experientes e a partilha com os colegas; E5 relatou a interligação do conhecimento acadêmico com a área da docência e E8 evidenciou a importância dos relatos dos residentes nas soluções de seus conflitos em sala de aula.

Os relatos de E3, E6, E8 e E4 evidenciaram que a predisposição em participar no PIBID influenciou no interesse pela docência. Portanto, os depoimentos mostraram que a aprendizagem da docência está relacionada: aos relatos de experiências nas reuniões do PRP, à participação em 
eventos da Área de Ensino como inicição à pesquisa, às observações e orientações dos preceptores e ao reforço positivo na participação no PIBID.

\section{Quadro 5 - Fase 3: Interesse Individual Emergente}

\begin{tabular}{|c|c|}
\hline \multicolumn{2}{|c|}{$\begin{array}{c}\text { A Fase } 3 \text { - Interesse Individual Emergente: agrupa os excertos que evidenciam a articulação de } \\
\text { conhecimentos, valores e sentimentos positivos que mantêm o estudante vinculado ao aprendizado da } \\
\text { docência }\end{array}$} \\
\hline $\begin{array}{c}\text { Admiração pelo } \\
\text { preceptor }\end{array}$ & $\begin{array}{l}\text { Eu fui escolhido por um dos professores mais legais. Eu achei sensacional porque o } \\
\text { professor G. é um professor muito querido (E1Q8) [...] e ele me deixou com muita } \\
\text { vontade de querer fazer alguma coisa parecida (E1Q8). } \\
\text { Eu aprendi com o professor G, um excelente professor, que mesmo que tenha alunos } \\
\text { difíceis de lidar, todos o respeitam, pois é amigo dos alunos (E2Q4) [...] e o modelo } \\
\text { de provas dele é um que eu posso usar (E2Q7). }\end{array}$ \\
\hline & $\begin{array}{l}\text { O programa mudou completamente a minha visão, eu tinha muito preconceito com } \\
\text { essa área de lecionar, um receio muito grande. Não conseguia falar em público, eu } \\
\text { tinha pânico. E ai eu terminei minha regência e me surpreendi: minha postura } \\
\text { mudou (E5Q9). } \\
\text { A sala que eu mais acompanhei os alunos eram muito interessados, só que você } \\
\text { tinha que dar um start para eles prestarem atenção [...] Então era uma coisa que a } \\
\text { gente sempre fazia: primeiro buscava a atenção deles para passar algum conteúdo } \\
\text { (E4Q8). }\end{array}$ \\
\hline
\end{tabular}

Apropriação de saberes: como "ser" professor
Como lá não tinha laboratório, praticamente o que a gente fazia de diferente, uma prática de osmose, qualquer coisa eles achavam interessante, eles participavam mais. Então a gente via que não é só jogar o conteúdo, mas algo que atrai eles (E7Q8).

Na Residência a gente tem aquele contato realmente com a sala de aula. A gente, digamos assim, sente como é ser professor (E8Q5).

Na Residência um dos objetivos é que a gente dê aula de fato... e dando aula você tem contato com a sala de aula, com o que é ser professor. Você lá na frente, você falando e quando você faz na prática é diferente (E2Q5).

Eu estou participando do PRP porque eu quero seguir na área de ensino como professor. É minha vontade desde que entrei no curso, quero sim na área de ensino (E10Q1).

Escolha pela carreira docente

Na verdade eu queria veterinária e eu tentei por alguns anos. Mas daí minha mãe pediu para eu tentar ciências Biológicas porque se aproximava mais da área e, se eu quisesse transferir meu curso no $1^{\circ}$ ano haveria essa possibilidade. Mas eu gostei tanto, que desisti da veterinária, eu continuei no curso por conta disso: eu gostei mesmo (E6Q7).

O PRP mudou minha visão quanto a ser professor no quesito de falar, de comunicar, de transmitir conhecimentos, de coisas que eu não sabia que poderia fazer. Dando aulas em sala de aula, não sabia que poderia ir para essa área (E3Q2).

Encontro com a profissão docente
No RPP, eu mudei completamente minha visão de como é ser professor: na ideia eu já tinha uma ideia previa, pois no ensino médio eu acabei auxiliando os alunos em aulas de reforço, eu já sabia como era auxiliar alguém a estudar. No PRP, na frente de uma turma inteira, eu mudei completamente minha visão e minha postura de falar às pessoas e transmitir conhecimentos (E5Q1). 


\begin{tabular}{|c|l|}
\hline $\begin{array}{c}\text { Importância das } \\
\text { atividades dos } \\
\text { estudantes no PRP }\end{array}$ & $\begin{array}{l}\text { Nós trazemos coisas diferentes dentro da sala de aula, como metodologias, aulas } \\
\text { demonstrativas que são mais recentes. Coisas que muitos dos professores não } \\
\text { tiveram na grade curricular deles lá no passado...ajuda o professor na parte } \\
\text { acadêmica e ele também ajuda a gente (E1Q9). }\end{array}$ \\
$\begin{array}{l}\text { O que eu mais gostei de estar indo na sala de aulas eram as alunas, que gostavam } \\
\text { bastante quando a gente ia, que ia ter coisas novas, eles gostam bastante de coisas } \\
\text { novas, né? (E7Q8). }\end{array}$ \\
\hline
\end{tabular}

Fonte: Elaborado pelos pesquisadores (2020).

Na fase 3, os residentes apresentaram interesse pela docência. Foi observado que E5 mudou sua postura e concepções negativas da docência com sentimentos de surpresa e superação, já E1 e E2 relataram que a convivência e admiração de seus preceptores influenciaram na vontade de querer realizar algo similar. A prática cotidiana in actu possibilitou a E4 e a E7 reflexão para a tomada de decisões ao revelarem, “Então era uma coisa que a gente sempre fazia: primeiro buscava a atenção deles para passar algum conteúdo” (E4Q8), "não se trata apenas de somente expor o conteúdo, mas sim, de algo que atraia os alunos para melhor apender” (E7Q8).

Para E8 e E2 é no contato com a sala de aula e na regência que se aprende a ser professor. Quanto à escolha pela profissão docente, E10 relatou ser uma decisão pessoal desde o início, no entanto, E6 disse não ter sido a primeira opção, mas ao cursar licenciatura afirmou ter gostado muito. Tanto E3 quanto E5 afirmaram que a participação no PRP contribuiu para mudanças no jeito de falar e de transmitir conhecimentos com posturas de um professor. E1 e E7 consideraram as atividades praticadas por eles como contributivas para aprendizagem dos alunos, e também do preceptor.

A nossa análise dos excertos acomodados nesta categoria evidenciaram, portanto, indícios de aprender/sentir o que é ser professor.

\section{Quadro 6 - Fase 4: Interesse Individual Bem Desenvolvido}

A Fase 4 - Interesse Individual Bem Desenvolvido: agrupa os excertos que evidenciam mais sentimentos positivos e mais conhecimentos, mais valores. $O$ estudante encontra-se muito envolvido e motivado, de modo que valoriza a oportunidade de envolver-se em atividades ou tarefas relacionadas à docência.

Minha experiência como professor? Ah... deu um gelinho no começo, você fala: Meu Deus do céu! Agora quem tem que dar aula sou eu (risos). Vou caprichar nisso daqui! E você tenta passar o conhecimento para o aluno, ele não compreendia bem, aí você tem que talvez usar algum outro exemplo do cotidiano dele, alguma coisa que encaixe com a aula e você vai adaptando aula. Não é rígido como você fez no

Vivências em sala de aula plano, não é aquilo, sempre tem alguma adaptação, sempre! (E2Q9).

A vivência em sala de aula é a maior delas porque você tem o contato com a sala de aula, conhecer a turma, quebrar aquele bloqueio inicial, começar a conviver diariamente e ver o retorno deles em questão de aprendizado, de afeto também, vai conhecendo melhor como é a vida de cada um, isso ajuda também na forma de você encarar as outras turmas (E4Q5). 


\begin{tabular}{|c|c|}
\hline & $\begin{array}{l}\text { O que eu mais gostei foi a vez que um residente bolsista não pôde ir e era um } \\
\text { assunto que eu adoro falar, que é o que eu faço. Daí eu assumi aula basicamente } \\
\text { inteira, os alunos interagiram com bastantes dúvidas, inclusive quando deu o sinal, } \\
\text { ficamos eu e uma outra residente na sala de aula, com mais duas alunas (E5Q7). }\end{array}$ \\
\hline $\begin{array}{l}\text { Percalços da profissão } \\
\text { docente }\end{array}$ & $\begin{array}{l}\text { Era uma sala muito difícil com vários grupinhos que não ficavam quietos em } \\
\text { nenhum momento, mesmo a gente pedindo, pouquíssimos respeitavam quando a } \\
\text { gente explicava (E1Q5). } \\
\text { Uma coisa ruim, você está dando aula, querendo transmitir o conteudo para alguém } \\
\text { e outras pessoas que não estão interessadas, acabarem atrapalhando. Você acaba } \\
\text { não atingindo o objetivo de fazer com que as pessoas aprendam (E3Q7). } \\
\text { Um aluno meio que não aceitava nossa presença em sala de aula, ele começou a } \\
\text { querer fazer arruaça na turma. E esse aluno puxava muito o resto da turma, } \\
\text { induzindo que não gostava da gente e o resto da turma ficava apreensiva (E8Q6). } \\
\text { Ela devia estar passando por momentos dificeis na vida pessoal, a gente até acha } \\
\text { que não estava apta no momento para estar assumindo uma sala de aula. Só que a } \\
\text { gente tem que se pôr no lugar do outro porque para ela não devia ser fácil. Imagino } \\
\text { que ela devia ser uma professora boa...os alunos não respeitavam ela e muitas vezes } \\
\text { eu fui para casa com raiva de ver as atitudes deles (E6Q8). }\end{array}$ \\
\hline $\begin{array}{l}\text { A pretensão de ser } \\
\text { professor no contexto } \\
\text { do PRP }\end{array}$ & $\begin{array}{l}\text { Eu pretendo ser professor com toda certeza! Pretendo assim que eu terminar ou até } \\
\text { antes, estar lecionando, dando aulas de Ciências ou Biologia, de preferência } \\
\text { Biologia, porque eu me dou melhor com adolescentes e jovens (E1Q4) } \\
\text { Eu quero ser professor, ter contato com a escola da melhor forma e a residência } \\
\text { proporciona isso(E3Q8). } \\
\text { Eu pretendo ser professor e ficaria muito satisfeito se isso acontecesse(E4Q4). } \\
\text { Eu pretendo porque como eu já entrei na licenciatura, né? Eu gostei e eu } \\
\text { pretendo(E7Q4). } \\
\text { Eu pretendo ser professora de Ciências/Biologia porque eu venho de uma família } \\
\text { de professores. Eu dei aulas em outras áreas (E6Q4). } \\
\text { Eu me vejo, principalmente como professora de Biologia. Eu gosto muito dessa } \\
\text { questão do ensino, mas tenho um pezinho digamos assim na genética (E8Q4). } \\
\text { Eu pretendo ser professor de Ciências ou Biologia porque eu gosto da área, de } \\
\text { verdade (E10Q4). }\end{array}$ \\
\hline Autorregulação & $\begin{array}{l}\text { Como eu falei, no começo eu não pretendia ser professor. Com o tempo fui } \\
\text { mudando minha opinião, e atualmente eu gostaria. Eventualmente eu vou acabar } \\
\text { indo pra sala de aula, não sei se é por resto da vida (E3Q4). } \\
\text { A minha visão de quanto a ser professor mudou ao participar do PRP, pois você tem } \\
\text { uma visão maior de como é realmente uma sala de aula, a gente vai com mais } \\
\text { frequência, não é como o estágio obrigatório, que você vai às vezes na escola (E7Q2). } \\
\text { Apesar de ter formação no magistério, eu já tinha um pouco de contato com a } \\
\text { docência, Mas eu nunca me vi na verdade com alunos, assim do Ensino Superior, } \\
\text { do Ensino Fundamental anos finais, eu sempre me via apenas com alunos dos anos } \\
\text { iniciais, mas com a convivência do PIBID foi crescendo um pouco mais minha } \\
\text { vontade, meu desejo de trabalhar com alunos, digamos mais velhos. Com a } \\
\text { Residência vi a oportunidade de eu aprender um pouco mais (E8Q1). } \\
\text { Reafirmou o que eu queria, por mais que a gente passe por algum contratempo, eu } \\
\text { gosto, eu só quis seguir na área na docência (E6Q2.) }\end{array}$ \\
\hline
\end{tabular}




\begin{tabular}{|l|l|}
\hline \multirow{1}{*}{$\begin{array}{l}\text { Participar do PRP contribuiu bastante porque eu soube lidar com algumas } \\
\text { dificuldades em sala de aula que eu achava que eu não saberia lidar. Eu soube ver } \\
\text { mais a necessidade do próximo (E6Q5). } \\
\text { Antes eu era aluna... e quando eu assumo uma sala de aula, dou uma aula e vejo } \\
\text { diferentes dificuldades, que jeito que eu tenho que agir com cada aluno, aquela } \\
\text { cautela (E6Q5). } \\
\text { Pra mim foi muito bom perceber isso porque confirmou um pouco mais minha } \\
\text { vontade que eu tinha já de estar em sala de aula, dando aula, transmitindo } \\
\text { conhecimento pra eles. Então foi uma experiência bem ... cresceu bastante meu } \\
\text { nível não só como aluna, mas como futura profissional em sala de aula (E8Q5). } \\
\text { Eu acho que eu cresci bastante nessa questão, porque como a gente dá aula várias } \\
\text { vezes ao ano, se for pra comparar, posso falar de mim, da primeira aula que eu dei } \\
\text { da turma que eu acompanhei pra última aula que eu dei, eu vi que eu consegui ter } \\
\text { um pouco mais de domínio da turma, até mesmo na questão da gestão de classe, um } \\
\text { pouco mais de confiança de dar aula, passar o conteúdo (E8Q5). }\end{array}$} \\
\hline
\end{tabular}

Fonte: Elaborado pelos pesquisadores (2020).

$\mathrm{Na}$ quarta e última fase do Interesse pela docência, os residentes sinalizaram em suas respostas um interesse mais aprofundado em relação às demais fases. Seus relatos manifestaram os sentimentos positivos e negativos sobre atividade docente, a perseverança na vontade de seguir a essa carreira e a metacognição frente as suas ações e percepções quanto à docência.

Notamos que E9 teve a preocupação de que o aluno aprendesse com contextualizações e adaptação do plano de aula, E4 valorizou a vivência diária em sala de aula, para obtenção do aprendizado e afeto dos alunos. E5 relatou a satisfação de ensinar conteúdo de sua preferência, juntamente com a interação dos alunos. Com relação às condições de trabalho da profissão, os residentes vivenciaram as situações corriqueiras como agitação (E1), desinteresse (E3), rejeição (E8), desrespeito (E6), e também a compaixão e empatia pela preceptora E6, ao relatar "Ela devia estar passando por momentos difíceis na vida pessoal... a gente tem que se pôr no lugar do outro porque para ela não devia ser fácil. Imagino que ela devia ser uma professora boa” (E6Q8).

Podemos perceber que o interesse pela docência foi manifestado pelas pretensões proferidas pelos residentes, E1 preferiu Biologia, pelo desejo de trabalhar com adolescentes e jovens; E7, na tentativa de melhorar o ensino; E4, como opção de profissão; E6 e E7, pela decisão inicial no ingresso da licenciatura e também pelo gosto, assim com E8 e E10. Os entrevistados relataram reflexões de autorregulação em vários aspectos: E3 tratou da mudança e gosto para prosseguir na profissão docente. E8 relatou sobre o aumento pelo gosto pelo magistério proporcionado pelo PRP, já E6 e E8 disseram que a participação no PRP contribuiu na reafirmação da vontade de ser professor: “Antes, eu era aluna... e, ao assumir uma sala, dei aula e vi diferentes dificuldades. 
Enfrentei o desafio de agir diferentemente com cada aluno, tive que ter cautela. E, se formos comparar a primeira com a última aula dala, percebi que consegui ter melhor domínio da turma, gestão de classe, estava mais confiante” (E8Q5).

Em uma visão geral das categorias, na Fase 1 - Interesse Situacional Acionado - foram efetivadas duas categorias: Despertar e Elementos relevantes. Nelas, foram alocados os excertos textuais dos residentes, vinculados aos indícios de interesse inicial da aprendizagem para a docência. Na categoria Despertar foram evidenciadas a vontade dos estudantes em experimentar como é ser professor, a concepção da necessidade da prática docente na assunção futura de uma sala de aula e a condição da tutoria (no contexto do PRP) de um professor mais experiente. Como elementos relevantes, a menção do recebimento da bolsa, como ajuda financeira, a certificação para futuros contratos empregatícios e o acréscimo em seu currículo do Programa de Residência Pedagógica demonstraram os elementos externos que valorizam o magistério e servem de "gatilho motivacional” (HIDI; RENNINGER, 2006 apud MARTIN, ARRUDA e PASSOS, 2016).

Na Fase 2 - Interesse Situacional Mantido - foi mostrado o envolvimento dos residentes em atividades que mantivessem seu interesse pela docência de maneira persistente, como por exemplo, as reuniões periódicas entre residentes, coordenadores e preceptores, as esporádicas como eventos de divulgação científica e a tutoria rotineira dos preceptores. Nessa fase, elencamos como categoria emergente a participação no PIBID pela maioria dos residentes entrevistados.

Na categoria Atividades significativas foi evidenciada a importância da participação no PRP para aprender os saberes da docência, no caso, a lidar com os alunos. Os eventos pontuais, mais específicos da Área de Ensino, como simpósios e eventos de divulgação, foram considerados pelos residentes meios de comunicação para aprender e pesquisar sobre a atividade docente.

A categoria Aprendizagem em grupo colaborativo referiu-se aos depoimentos dos residentes das contribuições de aprender juntamente com os pares por relatos de experiências, observações e práticas de microensino. O desenvolvimento do interesse pela docência manifestou-se pelos relatos dos residentes na Categoria Tutoria quanto à observação das ações didático-pedagógicas dos preceptores e à consideração de seus saberes experienciais.

A participação em anos anteriores, no PIBID, foi considerada pelos residentes, como fator motivacional e mantenedor do interesse pela docência, com relatos positivos e manifestação de vontade de continuar a formação inicial nesses moldes.

As categorias da Fase 2 - Interesse Situacional Mantido - corroboram o pensamento de Tardif: 
[...] a formação para o magistério está se transformando lentamente, mas na direção certa, dando um espaço cada vez maior aos professores de profissão, os quais se tornam parceiros dos professores universitários na formação de seus futuros colegas (2014, p. 241).

Nesse sentido, acompanhar e vivenciar atividades juntamente com o professor de profissão contribui tanto para a formação inicial dos residentes quanto para manter o interesse pela docência.

A Fase 3 - Interesse Individual Emergente - referiu-se aos excertos textuais indicadores de interesse mais duradouro pela docência e pelos depoimentos de afetos positivos em relação ao magistério. Nela, foram evidenciadas cinco categorias: admiração pelo preceptor, apropriação de saberes de como "ser” professor, escolha pela profissão docente, o encontro com a profissão docente e a importância das atividades realizadas no PRP. Na categoria Admiração pelo preceptor, os residentes qualificaram o trabalho do professor regente como eficiente, e identificaram suas ações didáticas como modelos a serem seguidos, com manifestação da vontade em realizá-las. A segunda, A apropriação de saberes: como "ser" professor, apresentaram as narrativas das suas próprias práticas docentes em sala de aula. Nela, os relatos demonstraram, desde o aprendizado em iniciar a aula numa sala agitada, em proporcionar atividades novas como motivação até a prática in actu, que corresponde a comunicar-se em público de forma "professoral”.

A categoria Escolha pela carreira docente abarcou os fragmentos textuais nos quais os residentes narraram sua escolha pela carreira docente. Notamos a existência de acadêmicos que ingressaram na licenciatura com a intenção de se formar e não dar prosseguimento da profissão, e outros que viram a possibilidade de gostar do curso e pretender seguir a docência.

$\mathrm{Na}$ categoria, Encontro com a profissão docente foram dispostos os excertos com manifestação de afetos positivos pela docência. Os residentes expuseram a surpresa na descoberta de ações antes não percebidas, além das mudanças de preconceitos pela profissão e de posturas diversas, perante uma turma, proporcionadas pela participação no PRP.

A categoria Importância das atividades dos estudantes no PRP contemplou os relatos das ações em sala de aula no exercício da regência. Os residentes compreenderam a importância de recursos e instrumentos variados para ensinar, tanto para os alunos aprenderem, quanto ao preceptor ter conhecimento dos aparatos mais modernos. Uma vez que, no cotidiano e na coletividade que aprendemos e nos dizeres de Tardif é de que, “[...] se quero saber como realizar um trabalho qualquer, o procedimento mais normal consiste em aprendê-lo com aqueles que efetuam esse trabalho” (2014, p. 241), no caso da aprendizagem da docência o saber ocorre com os professores da Educação Básica: os preceptores. 
A quarta e última fase - Interesse Individual bem desenvolvido - compreendeu quatro categorias: Vivências em sala de aula, Percalços da profissão docente, Pretensão de ser professor e Autorregulação. Na categoria Vivências em sala de aula, os residentes manifestaram mais preocupação com a aprendizagem do que o ensinar propriamente dito, com cuidados na compreensão e contextualização do conteúdo, afeto e interação com os alunos. Em Percalços da profissão docente, os relatos dos residentes evidenciaram as mazelas do magistério vivenciadas por eles, e que são fatos do cotidiano da maioria das escolas, desde o desinteresse dos alunos, formação de pequenos grupos com conversas, presença e influência de aluno líder, falta de respeito até a saúde do professor.

À categoria A pretensão de ser professor no contexto do $P R P$ foram agrupados os trechos dos residentes que manifestaram vontade de prosseguir com entusiasmo o ofício de professor, seja de Ciências ou de Biologia. Eles atribuíram à participação no PRP, uma parcela contributiva de influência na volição.

Por fim, na última categoria denominada Autorregulação, foram reunidos os excertos textuais que revelaram instantes de reflexão dos residentes, na compreensão da docência. A passagem de aluno para ser professor nas regências, a autoanálise de aperfeiçoamento na gestão de classe, as assertivas para continuar a carreira foram dados elencados nas entrevistas.

A Autorregulação, compreendida por nós, como o ápice do desenvolvimento pela docência, se efetiva pelo fato de que é intrínseco ao sujeito, numa direção para a autonomia, seguir sem apoiar-se em elementos externos de motivação, mas sim, de mobilização. Afinal, a [...] "motivação é externa, ao passo que a mobilização é um fenômeno interno: motiva-se alguém de fora, enquanto mobiliza-se a si mesmo de dentro” (CHARLOT, 2014, p. 74).

Por sua vez, os depoimentos analisados condisseram com Pimenta (2014, p. 11), ao afirmar que as relações entre as instituições formadoras e o campo profissional podem "[...] propiciar ao aluno em formação oportunidades para rever e aprimorar sua escolha pelo magistério”, e o PRP é uma dessas possibilidades.

Por fim na próxima seção apresentamos as considerações da pesquisa.

\section{Considerações finais}

O Programa da Residência Pedagógica é uma proposta de aproximação das instituições formadoras e os professores da Educação Básica para receberem os licenciandos no âmbito da docência. A expectativa repousa na aprendizagem dos residentes, no contexto social e real da sala de aula, e nos enfrentamentos do cotidiano escolar. 
Neste trabalho nos debruçamos no significante interesse de um grupo de estudantes participantes do referido Programa, norteados pelo Modelo de quatro Fases do Desenvolvimento do Interesse (MDI) de Hidi e Renninger (2006). Constatamos que ele passa por momentos de acionamento pela presença de elementos positivos pessoais e externos (Fase1).

Como elementos acionadores do interesse dos residentes pelo aprendizado da docência foram evidenciados: a vontade pessoal, a ajuda financeira da bolsa, a certificação para enriquecimento do currículo, a curiosidade e aquisição de experiência profissional. Do estágio inicial do despertar para o desenvolvimento do interesse, os elementos mantenedores do interesse inicial dos residentes para aprender a docência foram elencados: o envolvimento em atividades do PRP em grupo, a supervisão dos preceptores, a participação na comunidade científica e, anteriormente, o empenho no PIBID, um Programa de formação inicial anterior ao Programa Residência Pedagógica (Fase 2). Esses elementos são de grande relevância para o desenvolvimento do profissional de educação, em interações sociais com seus pares, os preceptores, os coordenadores, os alunos da sala de aula e os pesquisadores educacionais. Portanto, devem ser considerados e sua continuidade incentivada devido às enunciações positivas dos residentes para aprender a ser professor.

No que diz respeito à Fase 3, houve uma progressão e acumulação do interesse dos residentes pela profissão de professor, visto a persistência e o encorajamento nas atividades docentes, com sentimentos positivos de ordem pessoal para aprender a sê-lo, inclusive com mudanças de postura conforme os excertos os excertos apresentados no campo da Metodologia da pesquisa.

Por fim, a Fase 4 apresentou a predisposição subjetiva e a afetiva duradouras no envolvimento de atividades de longo período, como a regência na vivência das tarefas, os desafios enfrentados e superados e a amplificação da autonomia, que mantiveram o interesse do residente vinculado a programas de incentivo à docência. Esse envolvimento implica na pretensão do residente desejar ser professor.

Portanto, consideramos o PRP uma proposta auxiliar para a formação inicial dos licenciandos, com contribuições eficazes no que tange ao enfrentamento de situações, que certamente, os levarão a ter que decidir o que fazer ou o que deixar de fazer. Tais ações somente serão realizadas quando se coloca os pés em sala de aula, afinal, é lá que mora a principal razão do trabalho do professor: o aluno. Este tema não se esgota aqui. Muitos caminhos ainda poderão ser trilhados no que diz respeito à aprendizagem docente. Espera-se que com este estudo, novos caminhos possam ser trilhados e oferecidos àqueles que se manifestarem favoráveis ao estudo de outros focos da aprendizagem docente e também à aprendizagem de como ser professor. 


\section{Referências}

ARRUDA, Sergio de Mello; PORTUGAL, Khalil Oliveira; PASSOS, Marinez Meneghello. Focos da aprendizagem: revisão, desdobramentos e perspectivas. REPPE: Revista do Programa de PósGraduação em Ensino - Universidade Estadual do Norte do Paraná Cornélio Procópio, v. 2, n. 1, p. 91-121, 2018.

ARRUDA, Sergio de Mello; PASSOS, Marinez Meneghello; FREGOLENTE, Alexandre (2012). Focos da aprendizagem docente. Alexandria - Revista de Educação em Ciência e Tecnologia, Florianópolis, 5(3), 25-48.

CAPES. Programa de Residência Pedagógica. 2016. Disponível em: https://capes.gov.br/educacao-basica/programa-residencia-pedagogica. Acesso em: 10 nov. 2019.

CHARLOT, Bernard. Da relação com o saber às práticas educativas. 1 ed. São Paulo: Cortez, 2014.

HIDI, S. \& RENNINGER, K. A. The four-phase model of interest development. Educational sychologist., v. 41, p. 111-127, 2006.

HIDI, S., RENNINGER, K. A., \& KRAPP, A. Interest, a motivational variable that combines affect and cognitive functioning. In DAY, D. Y.; STERNBERG, R. J. (Eds.). Motivation, emotion, and cognition: integrative perspectives on intellectual functioning and development, Mahwah, NJ: Erlbaum, p. 89-115, 2004.

HOUAISS. Dicionário conciso. São Paulo: Moderna, 2011.

MARTIN, George Francisco Santiago; ARRUDA, Sergio Mello; PASSOS, Marinez Meneghello. O modelo de quatro fases do desenvolvimento do interesse aplicado à aprendizagem da docência. Investigações em Ensino de Ciências, v. 21, n.1, p.46-61, 2016.

MORAES, Roque; GALIAZZI, Maria Carmo (2011). Análise textual discursiva. Ijuí: Unijuí.

PIMENTA, Selma Garrido. Saberes pedagógicos e atividade docente. 2 ed. São Paulo: Cortez, 2014.

TARDIF, Maurice. Saberes docentes e formação profissional. 17 ed. Petrópolis: Vozes, 2014.

Recebido em: 28/05/2020

Aprovado em: 30/12/2020 